\title{
A systematic review and meta-analysis of the effectiveness of virtual reality as an exercise intervention for individuals with a respiratory condition
}

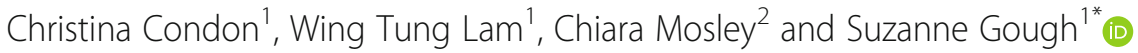

\begin{abstract}
Background: Respiratory diseases impose an immense health burden worldwide and affect millions of people on a global scale. Reduction of exercise tolerance poses a huge health issue affecting patients with a respiratory condition, which is caused by skeletal muscle dysfunction and weakness and by lung function impairment. Virtual reality systems are emerging technologies that have drawn scientists' attention to its potential benefit for rehabilitation.

Methods: A systematic review and meta-analysis following the PRISMA guidelines was performed to explore the effectiveness of virtual reality gaming and exergaming-based interventions on individuals with respiratory conditions.

Results: Differences between the virtual reality intervention and traditional exercise rehabilitation revealed weak to insignificant effect size for mean heart rate (standardized mean difference, SMD $=0.17 ; p=0.002$ ), peak heart rate $(\mathrm{SMD}=0.36 ; p=0.27)$, dyspnea $(\mathrm{SMD}=0.32 ; p=0.13)$, and oxygen saturation $\mathrm{SpO}_{2}(\mathrm{SMD}=0.26 ; p=0.096)$. In addition, other measures were collected, however, to the heterogeneity of reporting, could not be included in the meta-analysis. These included adherence, enjoyment, and drop-out rates.

Conclusions: The use of VRS as an intervention can provide options for rehabilitation, given their moderate effect for dyspnea and equivalent to weak effect for mean and maximum peak $\mathrm{HR}$ and $\mathrm{SpO}_{2}$. However, the use of virtual reality systems, as an intervention, needs further study since the literature lacks standardized methods to accurately analyze the effects of virtual reality for individuals with respiratory conditions, especially for duration, virtual reality system type, adherence, adverse effects, feasibility, enjoyment, and quality of life.
\end{abstract}

Keywords: Virtual reality, Virtual reality system, Exercise, Exergaming, Gaming, Intervention, Mixed reality, Augmented reality, Rehabilitation, Respiratory

\footnotetext{
* Correspondence: sgough@bond.edu.au

${ }^{1}$ Faculty of Health Sciences and Medicine, Bond University, Gold Coast, Queensland, Australia

Full list of author information is available at the end of the article
}

(c) The Author(s). 2020 Open Access This article is licensed under a Creative Commons Attribution 4.0 International License, which permits use, sharing, adaptation, distribution and reproduction in any medium or format, as long as you give appropriate credit to the original author(s) and the source, provide a link to the Creative Commons licence, and indicate if changes were made. The images or other third party material in this article are included in the article's Creative Commons licence, unless indicated otherwise in a credit line to the material. If material is not included in the article's Creative Commons licence and your intended use is not permitted by statutory regulation or exceeds the permitted use, you will need to obtain permission directly from the copyright holder. To view a copy of this licence, visit http://creativecommons.org/licenses/by/4.0/. The Creative Commons Public Domain Dedication waiver (http://creativecommons.org/publicdomain/zero/1.0/) applies to the data made available in this article, unless otherwise stated in a credit line to the data. 


\section{Background}

Respiratory diseases impose an immense health burden worldwide and affect millions of people on a global scale [1]. Chronic obstructive pulmonary disease (COPD), lung cancer, acute respiratory infections, tuberculosis, and asthma are the five most common respiratory conditions [1]. The affected population commonly experience symptoms including coughing, excessive sputum production, and shortness of breath [1], as well as other repercussions including reduced quality of life, systemic inflammation, decreased exercise tolerance, deconditioning, and inactivity [2]. Reduction of exercise tolerance poses a huge health issue affecting the cystic fibrosis (CF) patients, which is caused by the skeletal muscle dysfunction and weakness and lung function impairment resulting from CF $[3,4]$.

Virtual reality (VR) is an emerging new technology that has drawn scientists' attention to its potential impact on rehabilitation. The American College of Sports Medicine identified that modern technologies, including virtual reality, are the upcoming trend for rehabilitation and promoting an active lifestyle [5]. Based on their systematic review, Butler and colleagues conclude that active videogames induce similar physiological demands, such as maximal heart rate, dyspnea levels, and energy expenditure during training as traditional exercise modalities [6]. Obtaining clinical control, particularly in chronic respiratory conditions, can have systemic effects for the patient from length of hospital stay to quality of life. Gomes et al. recognized a key pillar of clinical control in pediatric populations with asthma and further concluded that rehabilitation utilizing VR exergaming was beneficial in improving cardiorespiratory fitness and symptoms relief in children with asthma [7]. Almeida and Rodrigues provided statistically significant evidence advocating for the implementation of VR in pulmonary rehabilitation program by highlighting its benefits on symptom relief, improved health-related quality of life, shorter duration of hospitalization, and reduction of healthcare cost [8].

Compliance is a pivotal factor influencing the effects of the rehabilitation program, especially for chronic disease. Unfortunately, poor patient compliance is a common issue, observed among studies and it is associated with frequent exacerbations of symptoms and more hospital admissions $[9,10]$. Among asthma patients, fear of exacerbation contributed to non-compliance and poor participation rate of physical activities, although research has clearly pointed out the unlikelihood of such adverse events during exercise [10]. Burr et al. suggested a clinical guideline to further assist the physicians to develop exercise guidelines for their clients, based on their condition and personal goals, with only $26(3.4 \%)$ out of 770 pre-screened participants reported the occurrence of mild adverse events [10]. The potential benefits of physical activity outweigh the risks and a strategy to promote compliance can be the key to respiratory rehabilitation. Home-based exercise training programs provide an opportunity for patients with CF to continue engaging in physical activities after they are discharged from hospitals, where they were constantly under supervision. However, observational studies involving home-based exercise programs [9] and clinical guidelines [10] both revealed inconsistent results in adherence which potentially led to unsatisfactory outcomes.

Exercise programs incorporating video game activities (VGA) provide an alternative to pulmonary rehabilitation programs. Besides the health benefits, VGA has the capability to affect enjoyment, adherence, and motivation to physical activities, especially in the young population [6]. Virtual reality gaming (VRG) is reported to be preferable to traditional exercise in CF and COPD studies because it is both enjoyable and can easily be implemented in their daily life $[11,12]$. One of the challenges incorporating VR into a rehabilitation program is to achieve high training loads needed to guarantee training effects [11]. Rutkowski et al. examined the effect of virtual reality systems (VRS), which is an umbrella term for virtual reality (VR), virtual reality gaming (VRG), augmented reality (AR), and mixed reality (MR). They highlighted the similarities between exercise incorporated VRS and traditional rehabilitation exercise in body movements [12]. Other studies supported the previous claim and proved rehabilitation programs utilized VRS elicit similar physiological outcomes, such as improved exercise capacity and responses including heart rate [13]. VRS are developed with the purpose to engage users by creating interactive and stimulating environments via visual, audio, and/or hepatic stimulus [14]; by encouraging engagement, VRS have a promising potential to increase motivation and compliance to exercise programs $[15,16]$.

The feasibility of using exergaming-based intervention as an alternative to traditional exercise intervention is still ambiguous with limited unbiased research conducted. Finite evidence was provided on feasibility and adverse events [16]. Most of the studies were confined by their small sample size and the preselection of relatively healthy participants $[6,9,12,13]$. Due to the dynamic nature of this field, it is imperative that the literature targets the most recent findings. The current systematic review aims to provide a unique exploration beyond the scope of previous reviews, which have primarily focused on active video games integrated within the treatment of chronic respiratory diseases, cystic fibrosis, or obstructive respiratory conditions. The purpose of this systematic review is to investigate the most 
current literature that examines the effectiveness of VR gaming and exergaming-based interventions in individuals with a respiratory condition and to provide further direction and recommendations toward future research.

\section{Methods}

A systematic review and meta-analysis following the PRISMA guidelines was performed to explore the effectiveness of VRS gaming and exergaming-based interventions on individuals with respiratory conditions.

\section{Search strategy}

From September 2019 to November 2019, databases were systematically searched: PubMed, Cumulative Index to Nursing and Allied Health Literature (CINA HL), Embase, Medline, Web of Science, and Cochrane library. After an initial search with mutually agreed search terms, an extensive search strategy was created, and search terms were individualized for each database with results being entered into a reference management tool (Endnote v9). An additional search using all identified terms and index words was done. The search terms used can be placed in three categories: condition, virtual reality, and gaming (Table 1). Reference lists were researched and collated manually and independently by two reviewers (CC and WL). Manual searches of the gray literature revealed no additional relevant results.

\section{Study selection}

Two reviewers (CC and WL) independently searched the databases systematically to identify relevant articles. Relevant results were entered into a reference management tool (Endnote v9) and duplicates were removed. Eligibility screening of articles was done independently by the reviewers. Additionally, articles that met the inclusion criteria were screened for further eligible studies. Conference abstracts as well as those where full text was not available were removed. The two authors compared studies for inclusion and exclusion. A third author (SG or CM) resolved discrepancies in decision-making. No language restrictions were applied to the search; however, all search results were written in English.

Overall, 3766 articles were identified after the process of literature search utilizing the search strategy. After an initial abstract and title screening by two independent reviewers (CC and WL), 72 articles were deemed relevant and eligible. All 72 full-text articles were subjected to the inclusion and exclusion criteria (Table 2). Twenty-two relevant articles were selected from 3766 potential papers using the PRIS MA process (Fig. 1). Seven articles were identified as pilot or feasibility studies, while the remaining articles were either systematic reviews (SR) $(n=4)$, randomized controlled trials (RCTs) $(n=6)$, or observational studies $(n=5)$. The Joanna Briggs Institute (JBI) critical appraisal tools were used to evaluate quantitative and quality evidence $[17,18]$ of the included studies.

\section{Data extraction}

Tables were used to adduce data extracted from included studies; authorship, geographic region, research type, population statistics, condition, duration, intervention type and comparator (Table 3), and outcome measures, adverse effects, limitations, and findings (Table 4) were recorded. The data extraction was completed by two reviewers (CC and WL).

Table 1 Search terms

\begin{tabular}{lll}
\hline Condition & Virtual reality & Gaming \\
\hline Pulmonary disease, chronic obstructive & Virtual reality & Exergaming \\
Respiratory condition & Virtual reality exposure therapy & Video games \\
Respiratory tract diseases & Augmented reality & Gaming \\
Restrictive pulmonary disease & Mixed reality & Game \\
Chronic obstructive pulmonary disease & & PlayStation \\
Lung cancer & & Wii \\
COPD & & Nintendo \\
Chronic bronchitis & & Kinect \\
Emphysema & & Xbox \\
Asbestosis & & Interactive games \\
Asthma & & \\
Cystic fibrosis & & \\
CF & & \\
Bronchiectasis & & \\
\hline
\end{tabular}


Table 2 Inclusion and exclusion criteria

\section{Inclusion criteria}

Quantitative, qualitative, mixed method, narrative, case control and descriptive studies, randomized and non-randomized control trials, quasi-randomized trials, and case reports and surveys are all considered.

Participants are individuals with a clinical diagnosis of respiratory conditions. Respiratory conditions include chronic respiratory diseases (asthma, bronchiectasis, chronic obstructive pulmonary disease (COPD), cystic fibrosis (CF), bronchiectasis, restrictive pulmonary disease, lung cancer)

Studies include an intervention involving any form of virtual reality (VR) gaming, augmented reality gaming, mixed reality gaming, exergaming, video game, console game, or game-based interventions that require players to perform physical exercise that becomes part of their rehabilitation.

\section{Exclusion criteria}

Interventions that are not requiring participants to perform any

physical actions during the game, for example, educational games.

Article that is not a full-text paper (e.g., thesis, conference abstract) or has no final data to be further analyzed.

Article that is not published in English.

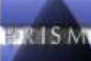

PRISMA 2009 Flow Diagram
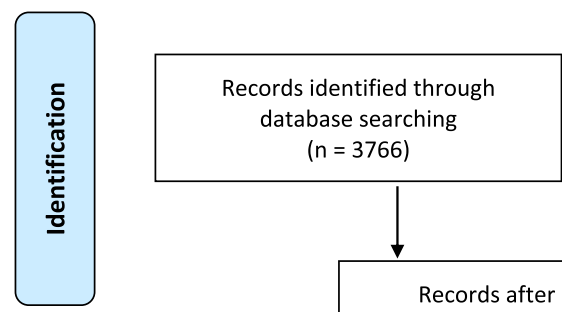

Records identified through other

sources

$(\mathrm{n}=0)$

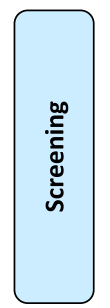

Records after duplicates removed

( $n=2186)$
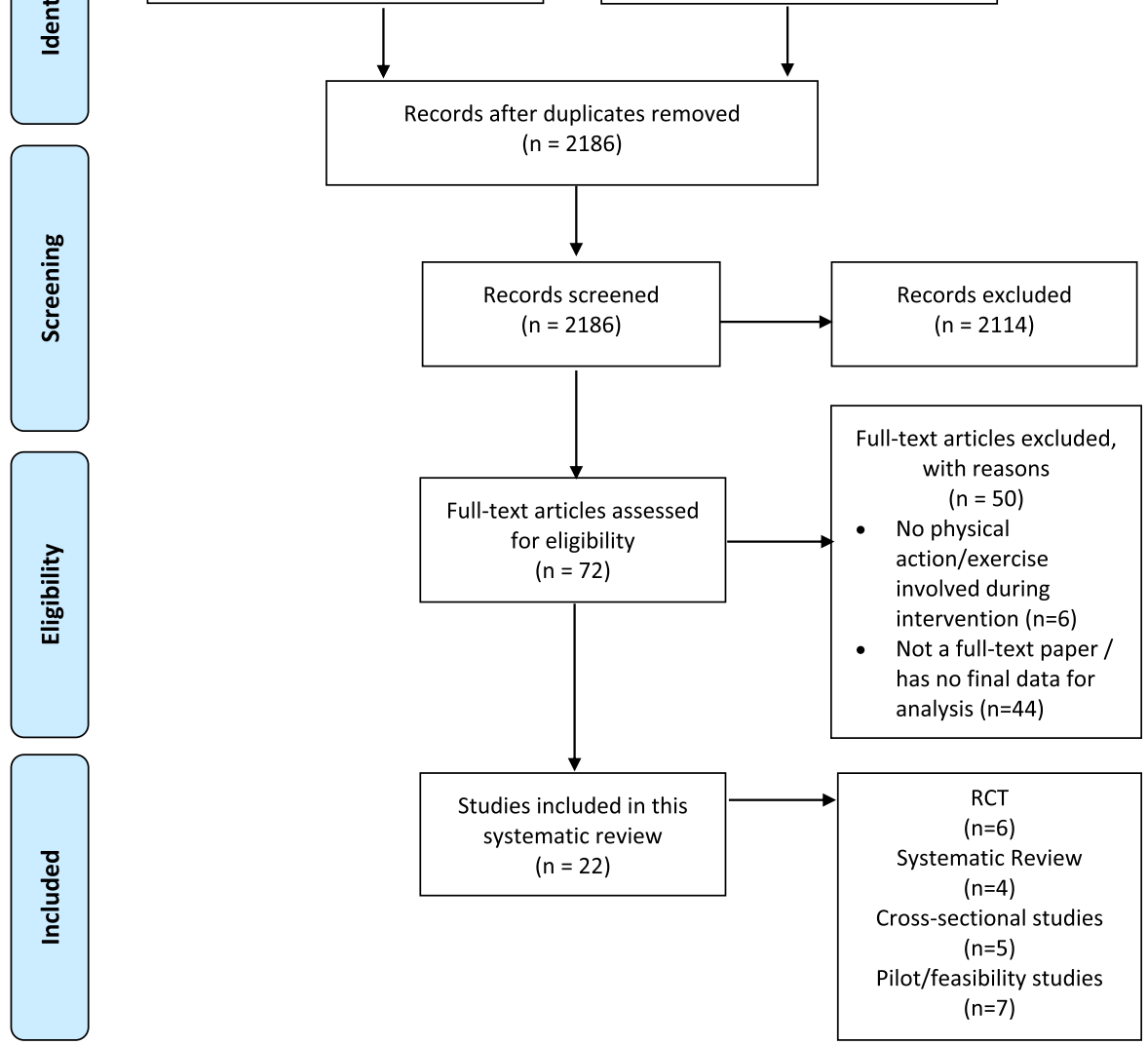

Fig. 1 PRISMA flow diagram for article inclusion 


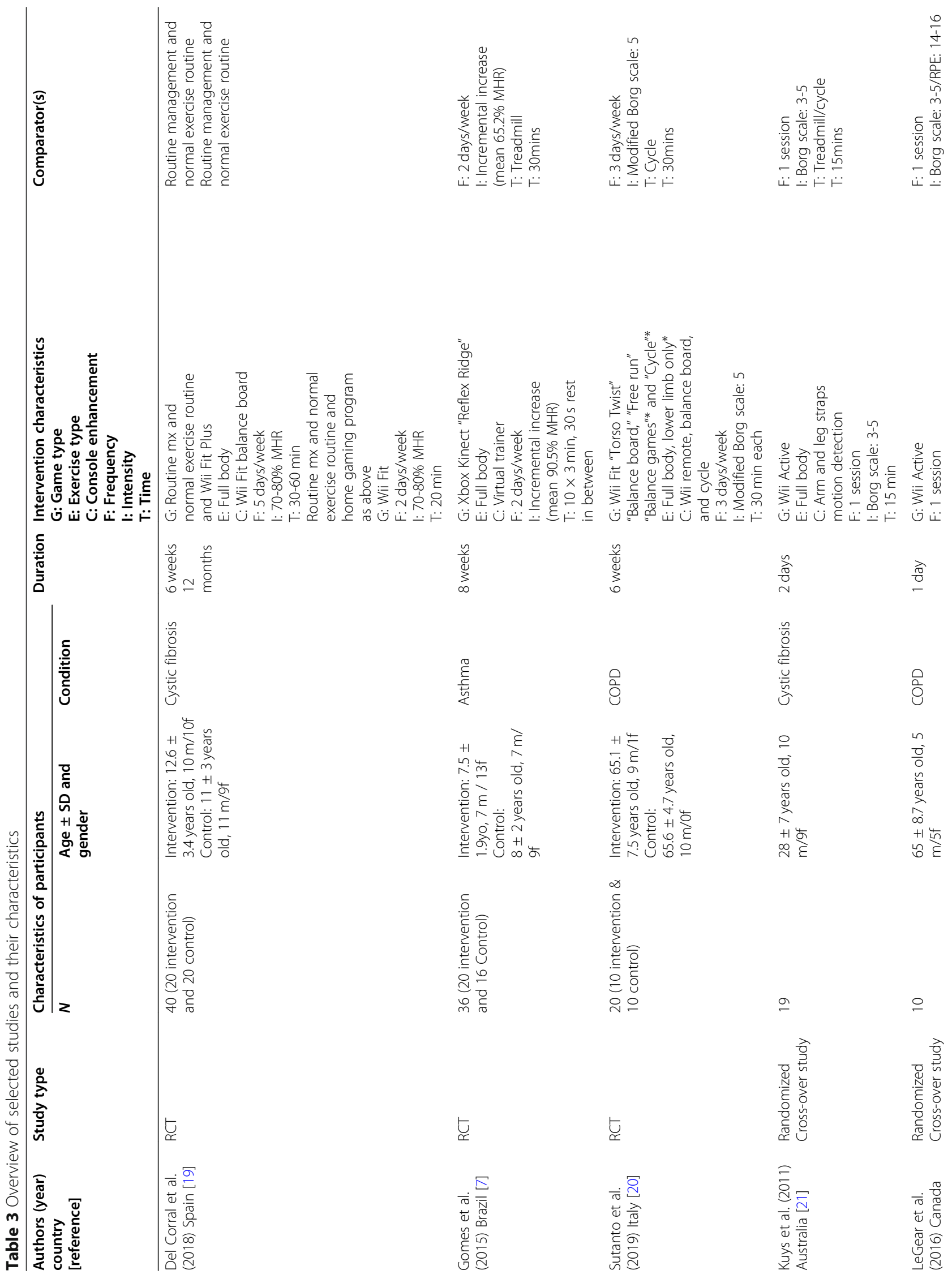




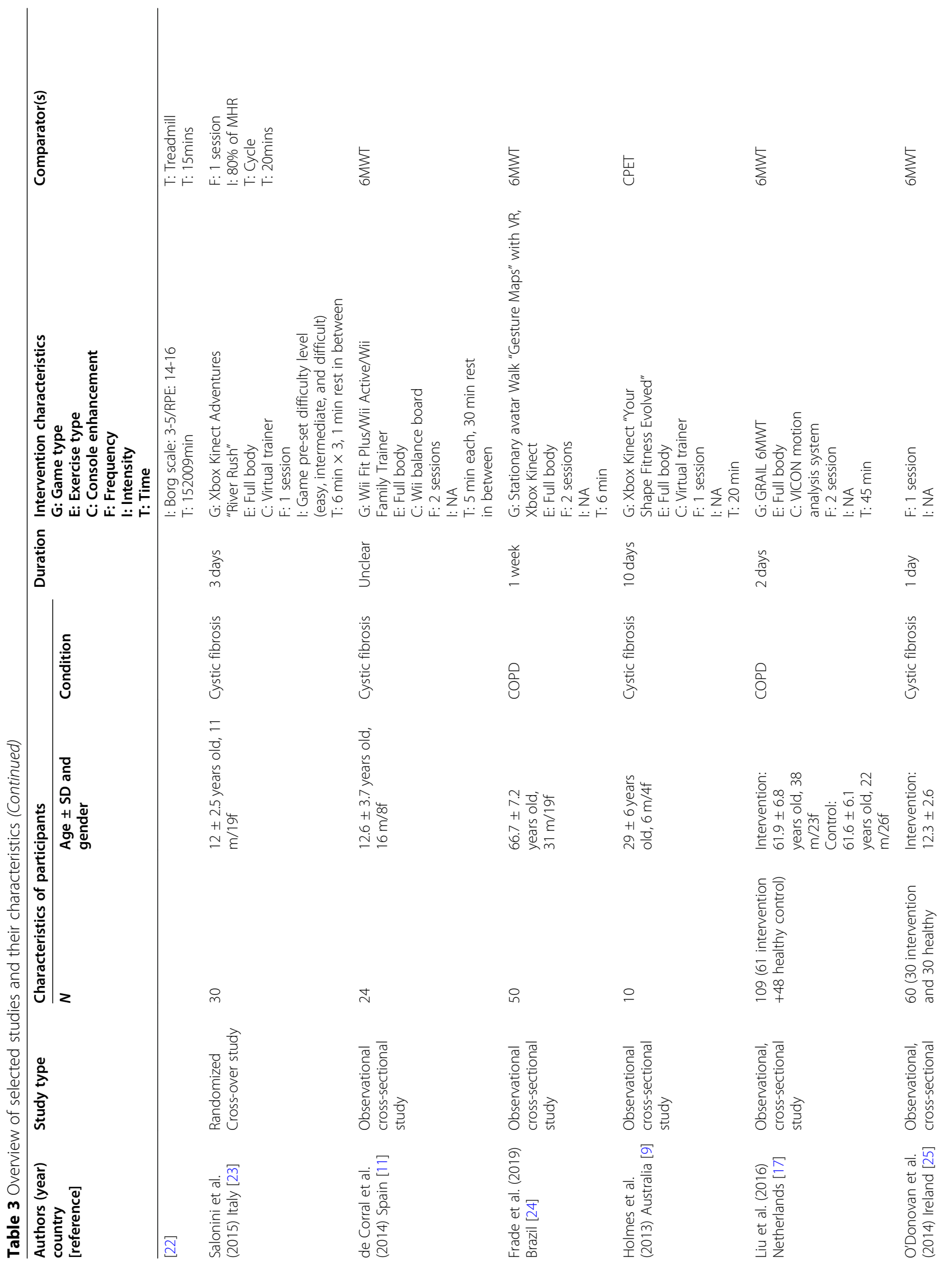




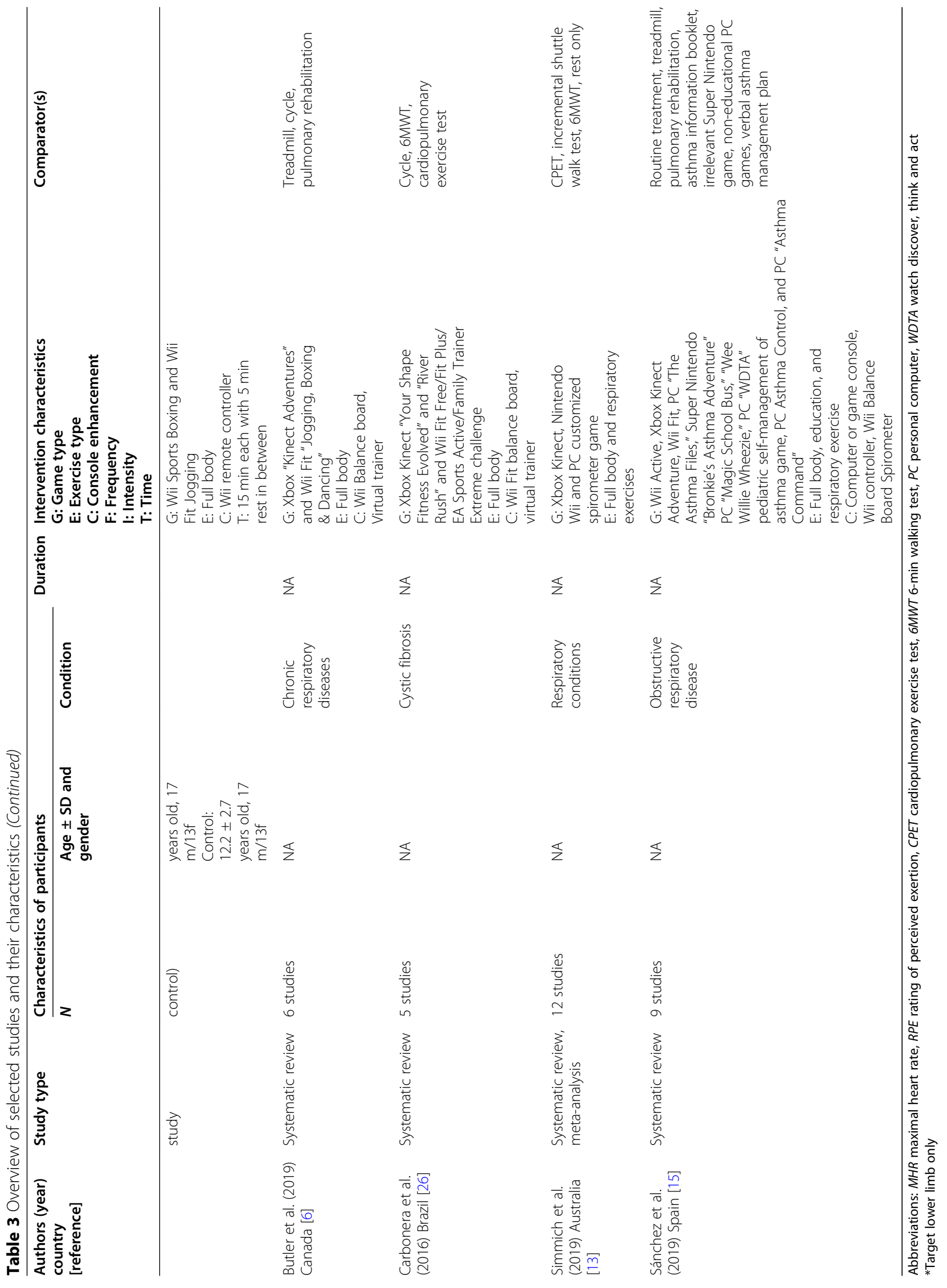




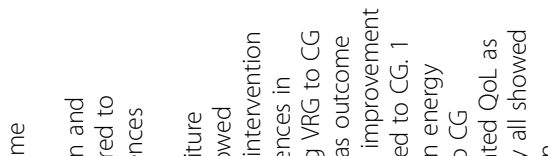

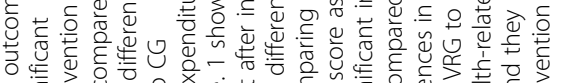

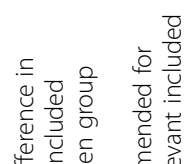

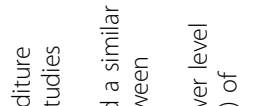

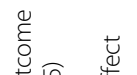

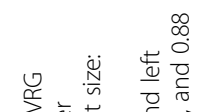

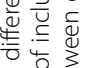

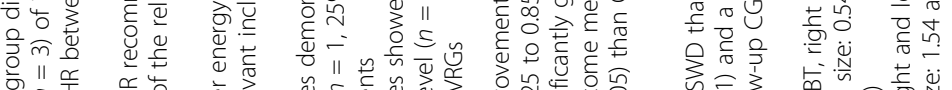

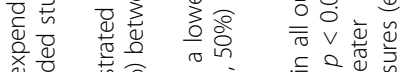

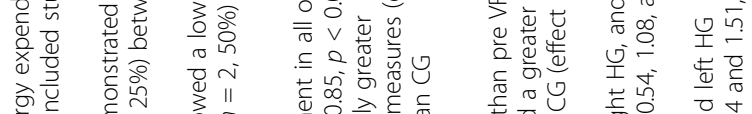

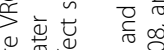

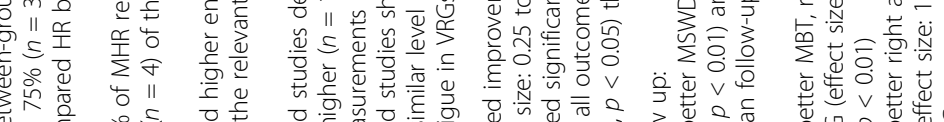

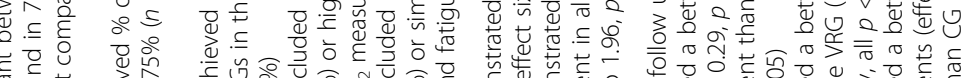

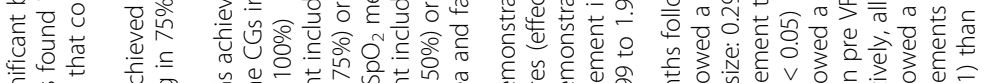

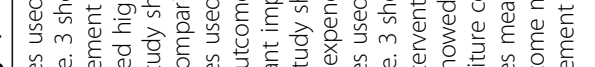

$\overline{\bar{\sigma}}$

$\frac{\theta}{+}$

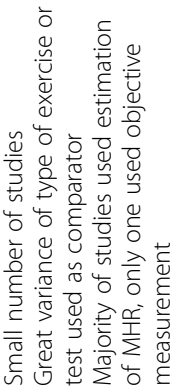

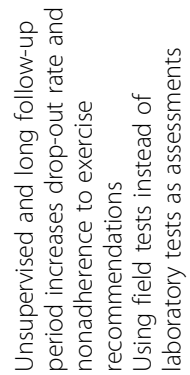




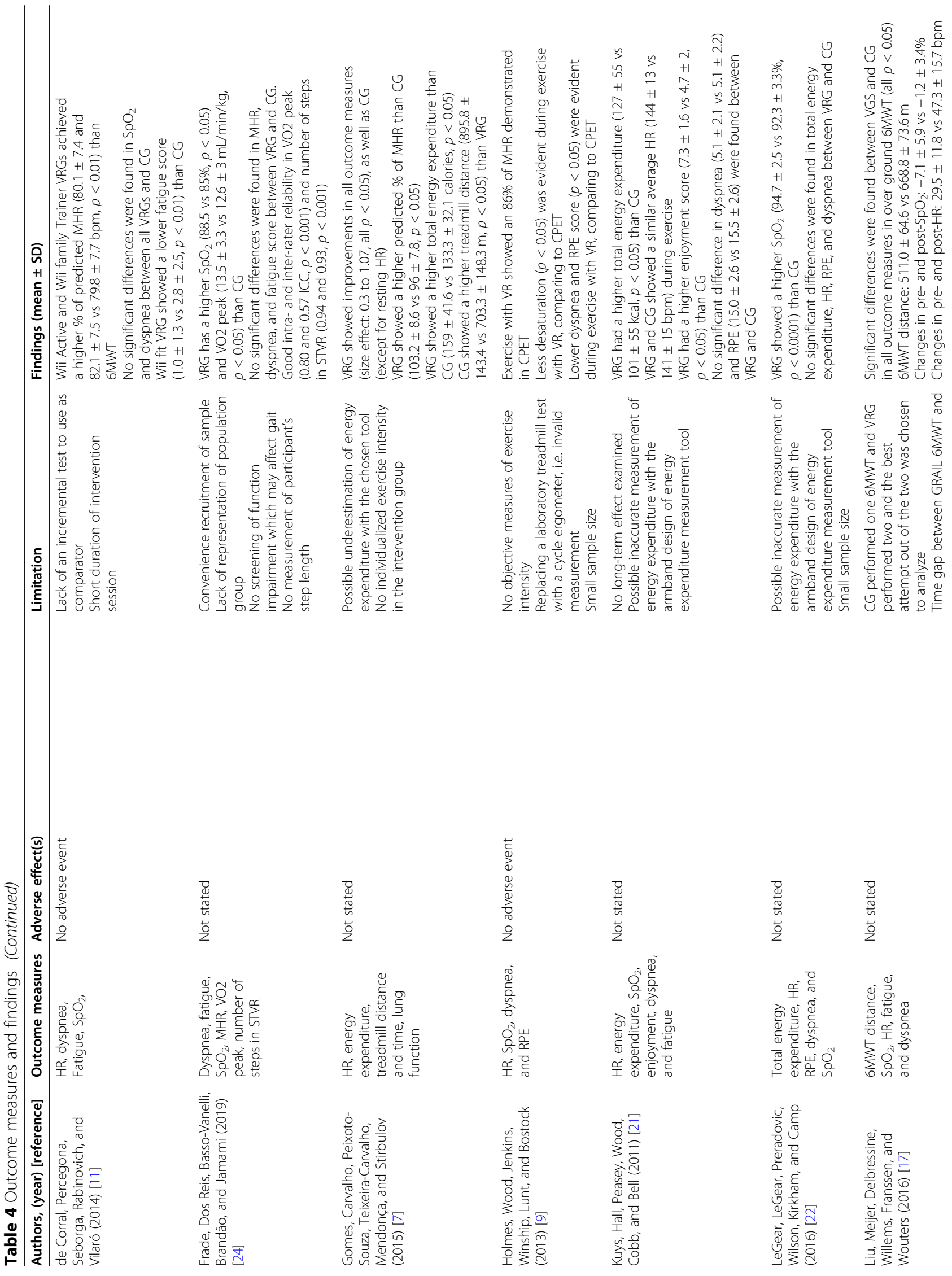




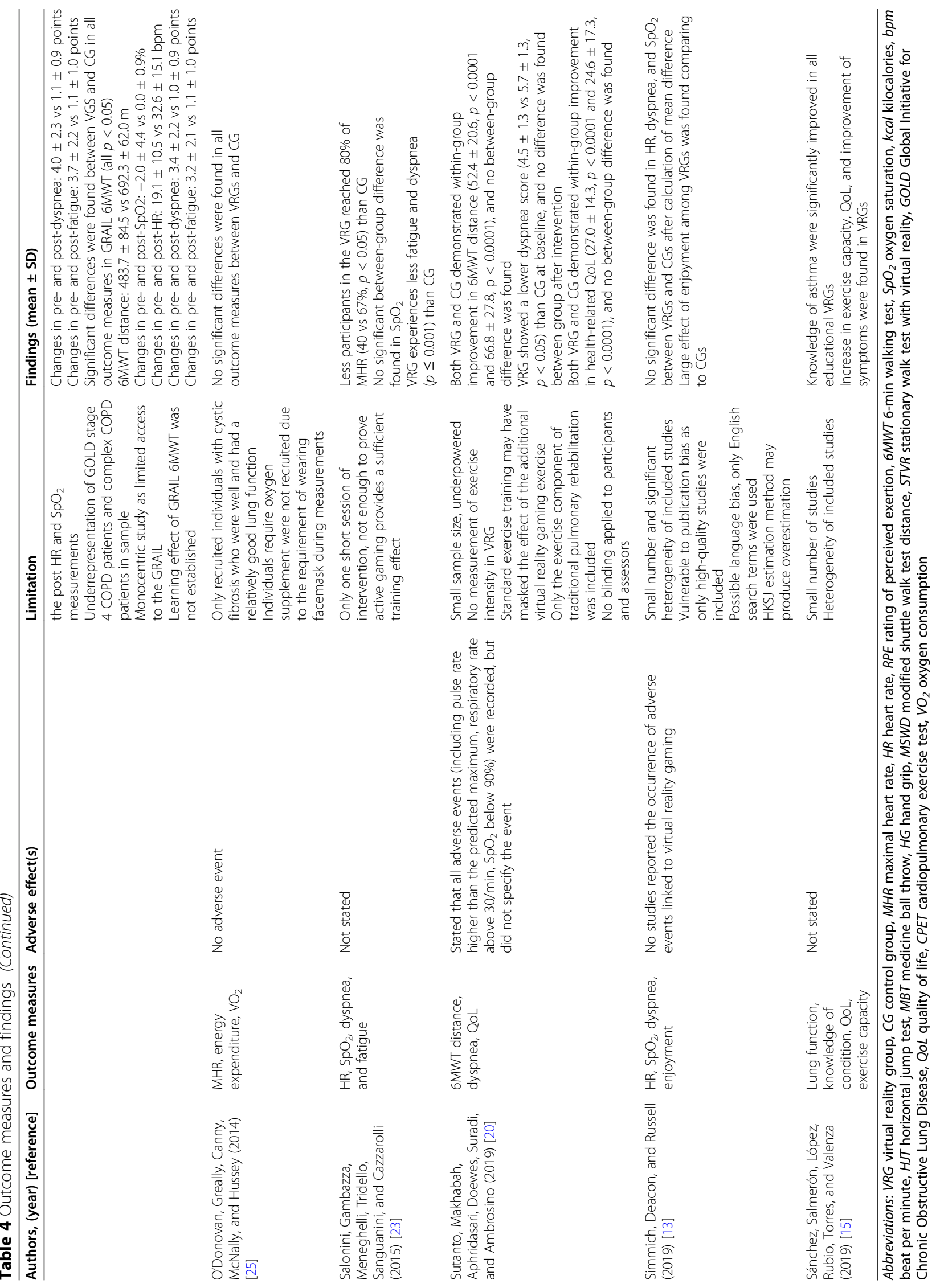


Table 5 Quality analysis using Joanna Briggs Institute critical appraisal tools [18, 27, 29]

\begin{tabular}{|c|c|c|c|c|c|c|c|c|c|c|c|c|c|c|}
\hline \multirow[b]{2}{*}{ Author(s) } & \multicolumn{14}{|c|}{ JBI Critical Appraisal Checklist for Systematic Reviews and Research Synthesis } \\
\hline & Q1 & Q2 & Q3 & Q4 & Q5 & Q6 & Q7 & Q8 & Q9 & Q10 & Q11 & & & Total \\
\hline Butler et al. [6] & Y & Y & Y & Y & Y & Y & N & $\mathrm{N}$ & $\mathrm{N}$ & N & Y & & & $7 / 11$ \\
\hline Carbonera et al. [26] & Y & Y & Y & Y & Y & Y & $\mathrm{N}$ & $\mathrm{N}$ & Y & $\mathrm{N}$ & Y & & & $8 / 11$ \\
\hline Simmich et al. [13] & Y & Y & Y & Y & Y & $\mathrm{N}$ & N & Y & Y & $N$ & Y & & & $8 / 11$ \\
\hline \multirow[t]{2}{*}{ Sánchez et al. [15] } & Y & Y & Y & $\mathrm{N}$ & Y & Y & $U$ & $\mathrm{~N}$ & $\mathrm{~N}$ & Y & Y & & & $7 / 11$ \\
\hline & \multicolumn{14}{|c|}{ JBI Critical Appraisal Checklist for Analytical Cross-sectional Studies } \\
\hline Author(s) & Q1 & Q2 & Q3 & Q4 & Q5 & Q6 & Q7 & Q8 & Q9 & Q10 & Q11 & Q12 & Q13 & Total \\
\hline Del Corral et al. [19] & Y & Y & $\mathrm{N}$ & N & Y & Y & Y & Y & & & & & & $6 / 8$ \\
\hline Frade et al. [24] & Y & $\mathrm{N}$ & Y & Y & Y & $\mathrm{N}$ & U & Y & & & & & & $5 / 8$ \\
\hline Holmes et al. [9] & Y & $\mathrm{N}$ & Y & Y & Y & N & Y & Y & & & & & & $6 / 8$ \\
\hline Liu et al. [17] & Y & Y & Y & Y & $\mathrm{N}$ & $\mathrm{N}$ & Y & Y & & & & & & $6 / 8$ \\
\hline \multirow[t]{2}{*}{ O'Donovan et al. [25] } & Y & Y & Y & Y & Y & $\mathrm{N}$ & Y & Y & & & & & & $7 / 8$ \\
\hline & \multicolumn{14}{|c|}{ JBI Critical Appraisal Checklist for Randomized Controlled Trials } \\
\hline Gomes et al. [7] & Y & Y & Y & N & N & Y & Y & Y & $\mathrm{N}$ & Y & N & Y & Y & $9 / 13$ \\
\hline Kuys et al. [21] & Y & Y & $U$ & $\mathrm{~N}$ & $\mathrm{~N}$ & Y & Y & Y & Y & Y & Y & Y & Y & $10 / 13$ \\
\hline Del Corral et al. [11] & Y & Y & Y & $N$ & $N$ & Y & $\mathrm{N}$ & Y & Y & Y & Y & Y & Y & $10 / 13$ \\
\hline LeGear et al. [22] & Y & $\mathrm{N}$ & $U$ & $\mathrm{~N}$ & $\mathrm{~N}$ & $\mathrm{~N}$ & Y & Y & $U$ & Y & Y & Y & $N$ & $6 / 13$ \\
\hline Salonini et al. [23] & Y & Y & Y & $\mathrm{N}$ & $N$ & Y & Y & Y & $U$ & Y & Y & Y & Y & $10 / 13$ \\
\hline Sutanto et al. [20] & $U$ & $U$ & Y & $\mathrm{N}$ & $\mathrm{N}$ & $\mathrm{N}$ & Y & $\mathrm{N}$ & $\mathrm{N}$ & Y & Y & Y & Y & $6 / 13$ \\
\hline
\end{tabular}

Key: $Y$ yes, $N$ no, $U$ unknown

\section{Assessment of methodological quality}

All included articles were processed for the quality of analysis relevant to the research methodology. Differences in opinion were resolved by discussion or by a third reviewer (SG or CM). The Joanna Briggs Institute (JBI) critical appraisal tools $[18,27]$ were recognized as a reliable tool to investigate variations of study design including RCT, systematic review, and observational studies [28]. Outline of the results of the detailed analysis was created (Table 5).

The interrater reliability for the observational and RCT indicated almost perfect agreement $(k=0.94)$ [30]. The interrater reliability for pilot studies indicated perfect agreement $(k=1)$ [30]. Most common problems encountered were randomization, assessor blinding, duration of study, and statistically significant population.

\section{Statistical analysis and synthesis}

Meta-essential Workbook 3 (Version 1.5) [31] was used to perform a meta-analysis to investigate the effect on respiratory functions for the VR and VR/exergaming interventions compared with traditional exercises. RCTs were the only data included in the meta-analysis due to the high-quality study method. Effect sizes for independent continuous variables were calculated as standardized mean differences (SMD). SMD was used in cases where different methods across studies were used to assess the outcome measures because different types of VR and exergaming types were used across trials. The effect size was calculated as the difference in the outcome measure, reported at the end of trial from the control group and experimental group, where SMD $\geq 0.8$ represented a large effect, 0.5-0.79 represented a moderate effect, and 0.2-0.49 a weak effect [32]. All standardized deviations were found within the included articles. Forest plots were completed on mean $\mathrm{HR}$, peak $\mathrm{HR}, \mathrm{SpO}_{2}$, and dyspnea on the difference between groups effect post-intervention. Articles were excluded from the meta-analysis where it was not comparable to a healthcare alternative.

\section{Results}

\section{Description of studies}

A total of 3766 studies were found through searches in PubMed, Cumulative Index to Nursing and Allied Health Literature (CINAHL), Embase, Medline, Web of Science, and Cochrane library. There were 22 articles that were included in this study and Table 1 outlines the selection process.

Out of these studies, three were conducted in Australia $[9,13,21]$, three were conducted in Brazil [7, 24, 26], two in Canada [6, 22], one in Egypt [33], three in Italy $[20,23,33]$, one in Ireland [25], one in the Netherlands [17], three in Spain [11, 15, 19], one in the UK [34], and four in the USA [35-38]. All eligible studies were published in English and were included in the quality analysis [27]. Of the 95 participants used in the 
meta-analysis, 49 (52\%) were female and 46 (48\%) were male.

The mean age and population in relation to conditions were analyzed from the literature. Six studies recruited individuals with CF (mean age 15.3 years, $n=189$ ) [9, 11, 19, 21, 23, 26], one article analyzed asthma (mean age 7.75 years, $n=36$ ) [7] and four articles analyzed subjects with COPD (mean age 64.96 years, $n=189$ ) [17, 20, 22, 24]. Recruitment of participants was undertaken either by selection from an external health database $[7,11,22,24$, $26,39]$ or from inpatient programs [19, 21, 40, 41]. One study did not comment on recruitment methods [9], nine studies situated their data collection within outpatient settings $[7,9,11,17,20,22-25]$. From these studies, six looked at the effects of VR/exergaming [7, 9, 11, 20, 23, $25]$, two analyzed the results of VR [22, 24] and one utilized augment reality [17], while only one article chose an inpatient setting to analyze effects with VR [21]. Lastly, one article researched the results of VR/exergaming intervention in the home setting [19].

All seven pilot studies were underpowered due to the small experimental groups $(n \geq 20)$. The pilot studies reporting mean age and population in relation to conditions are as follows: three pilot studies (mean age 67.75 years, $n=30)[34,35,39]$ discussed COPD, and one pilot study recruited subject with CF (mean age 9.3 years, $n=$ 13) [36]. One pilot article reviewed a combination of conditions including COPD, bronchiectasis, interstitial lung disease, and asthma (mean age 71.2 years, $n=40$ ) [33]. Whereas, Hoffmann et al. [37] investigated lung cancer (mean age 64.6 years, $n=7$ ), and Yuen et al. [38] investigated idiopathic pulmonary fibrosis exclusively (mean age 69.8 years, $n=20$ ), VR/exergaming was used as the experimental intervention in five pilots [33, 35, 37-39] and exergaming was investigated by two studies $[34,36]$. Only one study used a comparator of video games instead of a traditional exercise program [38]. Home-based exercise interventions featured in five pilot studies [34-38], and two in inpatient [33, 39].

Qualitative results were collated from thirteen articles: one analytical cross-sectional study [19], five RCTs [7, 2023] and seven pilot studies [33-39]. Two pilot studies [33, 38] were classified as RCT, according to JBI criteria. Quality analysis scores were completed, as described in the methods, as follows: The cross-sectional review was evaluated to be moderate to high quality $6 / 8$ [19]. The average score for the RCT was $8.2 / 13$. Three of the five RCTs achieved high-quality scores $9</ 13$; however, two articles $[20,22]$ reduced the average score. The lack of participant blinding, and randomization of groups contributed to their lower quality. Two pilot studies that were analyzed as RCTs [33, 38] were 5/13 and 11/13 respectively. The attributed difference in score was the absence of assessor blinding [33]. The pilot study score average was 5.4/9. The primary reasons for the relatively low score was ascribed to the fact that there were no designated control groups within the studies, and there was poor reliability of outcome measurements. The authors of this review focused on three qualitative findings to synthesize the results: adherence, enjoyment, and drop-out rate. Adherence was reported in five articles: four pilot studies [34, 37-39] and one crosssectional review [19]. Enjoyment data was reviewed by four RCTs [20-23] and one cross-sectional [19]. Drop-out rate was reported by seven articles: two RCTs [7, 20], four pilot [33, 35, 36, 39], and one cross-sectional study [19].

\section{Synthesis}

In the synthesis, 15 RCTs, observational studies, and seven pilot studies were analyzed. Seven critical considerations that illustrate the effect of VGS on individuals with a respiratory condition were taken into consideration, including mean heart rate, peak heart rate, $\mathrm{SpO}_{2}$, dyspnea, adherence, enjoyment, and drop-out rate. The meta-analysis only considers data from RCT studies.

Three qualitative findings were synthesized in this review: adherence, enjoyment, and drop-out rates. The aim was to understand if VR/exergaming exercise programs impacted these aspects of rehabilitation. Additionally, this was to determine if the intervention had a long-term viability in clinics and realistic use for patients with chronic conditions. The definitions and parameters for each qualitative finding varied among the studies. Adherence timeframe varied between 1 to 12 months. Studies that reported two data points $[20,39]$ observed significantly higher adherence at the first reporting over the final time point. Only one article [34] reported an increase in attendance rate through the testing period with the use of the digital rewards method. Since four out of five studies [19-23] reported statistically significant increased enjoyment from the VR/exergaming interventions over traditional rehabilitation, this may encourage further research with more standardized parameters because of its potentially positive influence on participants. Lastly, only seven [7, 19, 20, 33, 35, 36, 39] of the twenty-two studies reported in this review analyzed drop-out rates. This potentially conflicts with the findings for enjoyment. These articles found significantly higher drop-out rates for the intervention group. Few articles reported the reasons for drop-out. However, for articles that did report results, their findings were inconclusively linked to the intervention. The qualitative results were suggestive of positive VR/exergaming subjective participant experience. However, the lack of consistency between the studies made clear conclusions difficult.

\section{Critical considerations \\ Outcome measures}

Outcome measures used in the articles and pilot studies varied as shown in Fig. 2. Only the measures of mean 


\section{A) Peak heart rate}

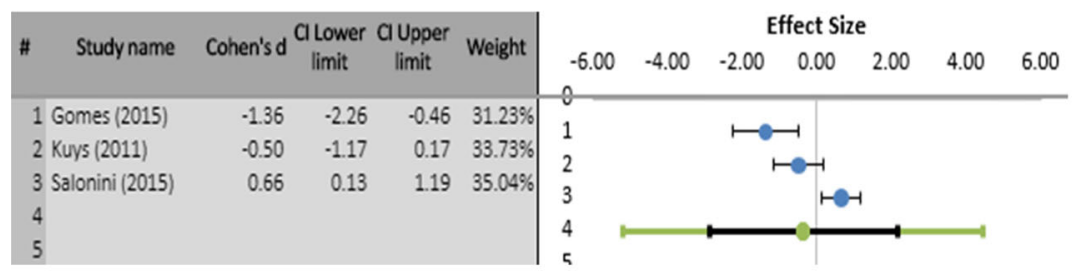

Effect size: -0.36 Standard error: $0.5995 \% \mathrm{Cl}(-2.88,2.16)$

$Z$ value: -0.62 Heterogeneity $I^{2}: 88.94 \%$

\section{B) Mean heart rate}

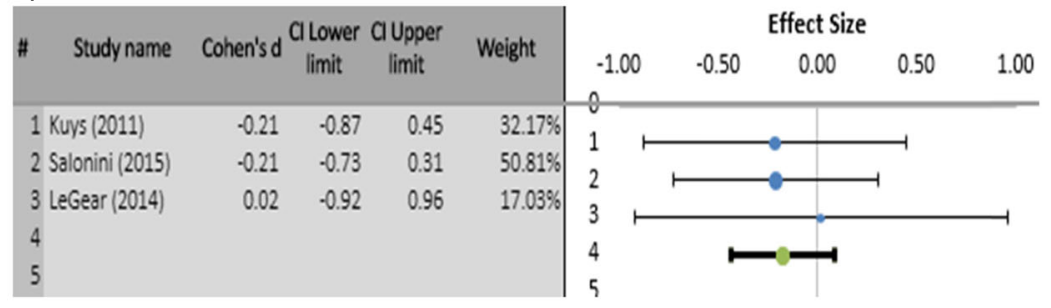

Effect size: -0.17 Standard error: $0.0695 \% \mathrm{Cl}(-0.43,0.09)$

$Z$ value: -2.84 Heterogeneity $I^{2}: 0 \%$

\section{C) $\mathrm{SpO2}$}

\begin{tabular}{|c|c|c|c|c|c|c|c|c|c|c|c|c|}
\hline \multirow{2}{*}{$\#$} & \multirow{2}{*}{ Study name } & \multirow{2}{*}{ Cohen's d } & \multirow{2}{*}{$\begin{array}{l}\text { CI Lower } \\
\text { limit }\end{array}$} & \multirow{2}{*}{$\begin{array}{l}\text { CUpper } \\
\text { limit }\end{array}$} & \multirow{2}{*}{ Weight } & \multicolumn{7}{|c|}{ Effect Size } \\
\hline & & & & & & -1.00 & -0.50 & 0.00 & 0.50 & 1.00 & 1.50 & 2.00 \\
\hline & del Corral (2014) & 0.54 & -0.06 & 1.13 & $21.90 \%$ & 1 & & & & & & \\
\hline & del Corral (2014) & 0.12 & -0.46 & 0.70 & $22.38 \%$ & 2 & & & & & & \\
\hline & Kuys (2011) & 0.23 & -0.43 & 0.89 & $19.07 \%$ & 3 & & & & & & \\
\hline & leGear (2014) & 0.82 & -0.16 & 1.80 & $11.04 \%$ & 4 & & & & & & \\
\hline & Salonini (2015) & -0.23 & -0.75 & 0.29 & $25.61 \%$ & 5 & & & & & & \\
\hline 6 & & & & & & 6 & & & & & & \\
\hline 7 & & & & & & & & & & & & \\
\hline
\end{tabular}

Effect size: 0.22 Standard error: $0.1795 \% \mathrm{Cl}(-0.25,0.69)$

$Z$ value: 1.3 Heterogeneity $I^{2}: 32.12 \%$

\section{D) Dyspnoea}

\begin{tabular}{|c|c|c|c|c|c|c|c|c|c|c|}
\hline \multirow{2}{*}{ \# } & \multirow{2}{*}{ Study name } & \multirow{2}{*}{$\begin{array}{c}\text { Cohen's } \\
\text { d }\end{array}$} & \multirow{2}{*}{$\begin{array}{l}\text { Cl Lower } \\
\text { limit }\end{array}$} & \multirow{2}{*}{$\begin{array}{l}\text { Cl Upper } \\
\text { limit }\end{array}$} & \multirow{2}{*}{ Weight } & \multicolumn{5}{|c|}{ Effect Size } \\
\hline & & & & & & -10.00 & -5.00 & 0.00 & 5.00 & 10.00 \\
\hline 1 & Kuys (2011) & 0.00 & -0.66 & 0.66 & $44.84 \%$ & 1 & & $\mathrm{HOH}$ & & \\
\hline 2 & LeGear (2014) & -0.59 & -1.12 & -0.06 & $55.16 \%$ & 2 & & ter & & \\
\hline 3 & & & & & & 3 & 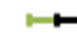 & & $=1$ & \\
\hline 4 & & & & & & 4 & & & & \\
\hline
\end{tabular}

Effect size: -0.32 Standard error: $0.2995 \% \mathrm{Cl}(-4.04,3.39)$

$Z$ value: -1.11 Heterogeneity $I^{2}: 49.46 \%$

Fig. 2 Forest plots demonstrating comparisons of outcome measures among included studies. a Peak heart rate. b Mean heart rate. c SpO2. d Dyspnea 
heart rate, peak heart rate, $\mathrm{SpO}_{2}$, and dyspnea met the statistical criteria needed to perform a meta-analysis.

Peak heart rate was assessed by five studies $[7,17,21$, $23,24]$. Mean heart rate was measured by four studies [11, $20,21,23] . \mathrm{SpO}_{2}$ was measured in five studies [11, 17, 20, $21,24]$. VO2 was analyzed in four studies [7, 11, 24, 25]. Dyspnea measured in five RCTs/observational studies [11, 17, 21-24] and four pilot studies [33, 36, 38, 39].

Duration was collated by total minutes of intervention use per experiment, six articles utilized the intervention for $\leq 30 \mathrm{~min}[11,17,21-24]$, while in three RCTs $[7,19$, $20]$ and four pilot studies $[33,35,37,38]$, the total intervention time was greater than $60 \mathrm{~min}$. Three different types of VGS (Nintendo Wii [11, 19-22, 25, 33, 35, 3739], Microsoft Xbox [7, 9, 23, 24], and others [17, 34, 36] were used. Compliance was measured in only one RCT [19] and four pilot studies [34, 37-39]. Enjoyment was reported in five RCTs [19-23] and two pilot studies $[37,39]$. Location types varied for these experiments. Nine studies [7, 9, 11, 17, 20, 22-25] looked at the effect of the intervention of subjects in an out-patient setting. One RCT [21] and two [33, 38] conducted their studies within in-patient settings. While one RCT [19] and four pilot studies [34, 35, 37, 38] investigated home-based intervention.

\section{Peak heart rate}

Three articles were analyzed for the effect size illustrated in Fig. 2a. Two articles [7, 21] found that the intervention did not achieve the HR peak average as compared with traditional exercise, with a SMD of -1.36 and 0.66 respectively. One article [23] showed a moderate effect of SMD 0.65. The average Cohen's $D$ (SMD -0.36; 95\% [CI, -2.88-2.16] $p=0.27 ; I^{2}=88.94 \%$ ) indicated a weak effect of the intervention over traditional exercise.

\section{Mean heart rate}

Three articles were analyzed for the mean heart rate effect of the intervention compared with traditional exercise. Kuys et al. [21] and Salonini et al. [23] found a weak effect (SMD -0.21 [-0.87-0.45]) and one [22] found an insignificant effect (SMD 0.02 [-0.92-0.96]). Figure $2 \mathrm{~b}$ presents the results of the meta-analysis in the format of forest plots. The average effect size reported as SMD -0.17 (95\% [CI, -0.43-0.09] $p=0.002 ; I^{2}=0 \%$ ), indicating an insignificant effect of the intervention on mean HR as compared with traditional exercise.

\section{$\mathrm{SpO}_{2}$}

Four articles evaluated the intervention effect on $\mathrm{SpO}_{2}$. Del Corral et al. [11] is represented twice as they evaluated two different VRG (Wii Fit and Wii Active) with separate data as shown in Fig. 2c, with one (Wii Active) showed insignificant result (SMD 0.12; 95\% [CI, -0.46-
0.7]) and the other (Wii Fit) showed a moderate effect (SMD 0.54; 95\% [CI, -0.06-1.13]). Two RCT studies [21, 23] reported a weak effect resulting in 0.23 [-0.43-0.89] and $-0.23[-0.75-0.29]$. One study [40] reported SMD = 0.82 [-0.16-1.8], which represents a large effect size. The overall effect was weak (SMD $=0.26 ; 95 \%[\mathrm{CI},-0.25$ 0.69] $p=0.096 ; I^{2}=66 \%$ ).

\section{Dyspnea}

Two articles evaluated dyspnea using the BORG dyspnea scale as shown in Fig. 2d. One article [21] showed no effect (SMD 0 [-0.66-066]) and another [22] showed moderate effect size (SMD 0.59 [0.06-1.12]). The average Cohen's $D(\mathrm{SMD}=0.32$; 95\% [CI, $-3.39-4.04] p=0.13$; $\left.I^{2}=49.46 \%\right)$ indicated a weak effect of the intervention over traditional exercise.

\section{Adherence}

Adherence varied in the collection and reporting of data. The data collection methods varied: for example, selfreported (weekly phone call $[19,37]$, exercise log book $[19,34,37]$, monthly e-mails [19], questionnaires [19, 38], mobile applications [34], direct supervision, with an in home visit [37], and supervision [39]. According to Hoffman et al. [37], adherence was calculated by the following equation: number of intervention completed/number of interventions prescribed, whereas Del Corral et al. [19] measured adherence as an average of $95 \%$ attendance per session at 6 th week and $35 \%$ at 12 th month. Burkow et al. [34] reported the additional use of digital rewards as a method to encourage adherence for home exercise programs, which is clinically relevant for determining cost-effectiveness. Burkow et al. [34] observed an average of $77 \%$ of participants reporting that digital rewards were influential to their attendance during the program. Leading to the average number of physical activity sessions per week was doubled from 2.9 (range 010, median 2) at baseline to 5.9 (range 3.3-10.33, median 4.8) during the testing period. Wardini et al. reported the mean adherence rate for the intervention group as $96.6 \pm 3.4 \%$ individuals' attendance per scheduled session [39]. Participants were deemed to be adherent with the program if they completed $>50 \%$ of sessions offered, using the equation: sessions attended/ sessions offered $=$ attendance rate. The authors report a $76 \%$ adherence rate, with a mean attendance rate of $64 \pm$ $35 \%$ at the 6-week endpoint [39]. Yuen et al. [38] estimated adherence by the completion of a post-study survey. Attendance of participants that completed the prescribed interventions, with a frequency of three times per week for $30 \mathrm{~min}$ per day, was $20 \pm 23 \%$. However, the adherence rate rose to $42 \pm 36 \%$ attendance when considering the recommended duration of $90 \mathrm{~min}$ per week for 12 weeks. 


\section{Enjoyment}

Enjoyment was analyzed as a component of adherence by five articles. Four articles reported enjoyment in favor of the intervention, statistically significant $[19,21-23]$ utilizing different assessment methods: Likert scale [19, 22], 10-point analog scale [21], and survey [23]. Kuys et al. [21] provided graphical data while three articles $[19,20,23]$ reported in percentage. One article [20] reported no statistical difference between the experimental and control groups, using the Saint George's Respiratory Questionnaire. Only one pilot study looked at the enjoyment of the intervention, resulting in an average rating (5.56/6) using the Likert scale. Del Corral [19] is the only study to measure enjoyment at the duration of 12 months. The lack of heterogeneity of assessment tools used throughout these articles excluded the data points from the meta-analysis.

\section{Drop-out rate}

Drop-out was reported in three articles [7, 19, 20] and four pilot studies [33, 35, 36, 39]. Rates ranged from 5\% [33] to 32\% [36]. Six articles and pilot studies distinguished drop-out between the experimental and control group or had a crossover design [7, 19, 20, 33, 36]. The collective mean drop-out rate was $16 \%$ higher for the intervention groups compared with the control groups ( $73 \%$ and $57 \%$ respectively). The predominant reason for drop-out was no response including incomplete sessions $[7,19,33,35]$ accounting for $37 \%$ of drop-out reported in both experimental and control groups. Exacerbation of symptoms [20,35], spontaneous rib fracture [35], and recurrent illness $[34,39]$ contributed to a mean average of $20 \%$ for the total drop-out. Of these, the articles that separated between experimental and control groups, exacerbation of symptoms [20,35], were only reported for the intervention group. Only one study [39] reported drop-out due to participants regarding the intervention type too simplistic $(n=2)$ or difficult $(n=2)$, totaling four participants (57\%) not included in the final analysis.

\section{Discussion}

This systematic review and the subsequent meta-analysis contribute novel information by broadening the scope of the literature search to include well-designed pilot and observational studies. Also, this report synthesizes the results of traditional outcome measures and qualitative data. The purpose of this systematic review and metaanalysis was to examine the current evidence on the effectiveness of VR gaming and exergaming-based interventions for individuals with a respiratory condition. Heart rate (peak and mean), dyspnea, and respiratory function $\left(\mathrm{SpO}_{2}\right.$ and $\left.\mathrm{VO} 2\right)$ were frequently reported to measure the effectiveness of exergaming and/or VR gaming intervention.
One of the main findings from this review is that exergaming-based interventions have been shown to produce an insignificant effect (SMD -0.17 [-0.43-0.09], compared with traditional rehabilitation) on mean HR. The difference can be potentially explained by the ambiguity in the indication of game intensity. The difficulty level of a video game is typically divided into levels (easy, moderate, and hard), which make it difficult to compare the intensity with both stationary bike and treadmill exercises. Moreover, the previous trial and review concluded that the HR response elicited by VGS achieves the recommendation intensity of training and will benefit the participants $[9,26]$. A similar trend was observed in maximum HR (SMD -0.36 [-2.88-2.16]), which was comparable with previous findings $[9,26]$. Salonini et al. [23] concluded a discontinuous HR trend with VRS and described gaming console exercise was similar to interval training with bursts of exercise followed by a short rest period. Although it resulted in a lower mean and maximum HR, the effect of high-intensity interval training is proven to be effective in improving compliance and cardiovascular fitness [23, 42].

Respiratory function is another frequently assessed outcome measure to determine the effectiveness of a rehabilitation exercise program. A weak effect was found in this meta-analysis of $\mathrm{SpO}_{2}$ (SMD 0.22, 95\% [CI, $-0.25-0.69]$ ), as VRS resulted in a lower level of oxygen depletion and potentially less intense physical activity than traditional forms of exercise. Millet et al. [43] found that maximal oxygen consumption varied by exercise modalities, while specific training may have an effect on reducing oxygen consumption as a learning effect when the body develops an effective way to execute the movements.

VRS are comprised of whole-body exercises that have no fixed pattern and resemble daily activities including side-stepping (e.g., to maintain balance) and bend forward (e.g., to reach a target), in which people are welltrained. Potentially, this can be attributed to the incapability of VRS to reach maximal exercise intensity, as it was a type of whole-body exercise designed for entertainment with integral rest periods (game loading time). As indicated in a previous study, only maximal exercise was able to create a similar level of oxygen saturation when comparing treadmill exercise and stationary bike exercise [22]. There is an unaddressed research gap on comparing whole-body exercise to treadmill and stationary bike exercise which makes the comparison of VRS and traditional exercise challenging.

Easing of symptoms including shortness of breath is one of the compelling benefits of physical activity. However, dyspnea is also one of the common adverse effects resulting from intense physical activity, especially when the participants fail to control their symptoms with 
medication and an action plan [10, 44]. VRS exercise induced a noticeably lower level of dyspnea compared with traditional exercise. As VRS exercise is considered an interval training equivalent [23], the regular resting periods may influence to ease the symptom, yielding a lower dyspnea score [45]. According to de Jong and colleagues [46], fear of physical activity-triggered dyspnea causes avoidance of physical exercise and deconditioning in individuals with COPD. The result of the metaanalysis showed that VRG intervention point toward a reduction of a reported dyspnea score. This may encourage exercise participation among individuals with respiratory disease and improve their exercise compliance.

There is currently no definitive evidence to determine the impact of VGS programs on individuals with respiratory conditions.

However, the aim of this review was to guide the structure and focus of further studies. VGS as an intervention, as a compactor of a traditional exercise program, can increase enjoyment, reduce symptoms (dyspnea), and maintenance of cardiovascular fitness in an outpatient and home setting. Future qualitative and mixed method studies to explore various stakeholder perspectives and economic evaluations of the use of VRS within the management respiratory conditions would provide valuable insights for service development.

\section{Limitations}

This review was limited by the heterogeneity of the studies and only six studies were included in the metaanalysis. A standardized value from the quality analysis could not be assigned to the articles, due to the lack of evidence and investigation of the JBI quality assessment tool. Enjoyment and adherence, which were crucial to the success of a pulmonary rehabilitation program, were not included in the meta-analysis because of the diverse outcome measures used [19-23, 37, 39]. Small sample size $[9,20,22,24]$ and biased target participants $[17,24$, 25] may lead to biased findings, with similar difficulties reported in previous systematic reviews $[6,13]$.

\section{Conclusion}

The results of this review illustrate that VRS can trigger physiological responses that benefit individuals with a range of respiratory conditions equal to that of a traditional exercise program. The use of VRS can provide options or adjuncts for rehabilitation, since the comparative results are equivalent to slightly diminished effect on heart rate, $\mathrm{SpO}_{2}, \mathrm{VO}$, dyspnea, and enjoyment. For those who only have access to a home program, VRS may be an effective and alternative method if initially supervised by a trained allied health professional. Adapting a VRS experience to focus on improving the respiratory outcomes and recovery of function for these individuals is a crucial factor for symptom reduction and quality of life. The field of VR/exergaming is dynamic; thus, it is essential that the most current and inclusive research guides clinical therapies.

\section{Abbreviations \\ VR: Virtual reality; VRS: Virtual reality systems; COPD: Chronic obstructive pulmonary disease; CF: Cystic fibrosis; VRG: Virtual reality group; AR: Augmented reality; MR: Mixed reality; CINAHL: Cumulative Index to Nursing and Allied Health Literature; CG: Control group; MHR: Maximal heart rate; HR: Heart rate; RPE: Rating of perceived exertion; 6MWT: 6-min walking test; $\mathrm{SpO}^{2}$ : Oxygen saturation; HJT: Horizontal jump test; MBT: Medicine ball throw; HG: Hand grip; MSWD: Modified shuttle walk test distance; \\ STVR: Stationary walk test with virtual reality; GOLD: Global Initiative for Chronic Obstructive Lung Disease; QoL: Quality of life; \\ CPET: Cardiopulmonary exercise test; $\mathrm{VO}^{2}$ : Oxygen consumption; JBI: Joanna Briggs Institute; SMD: Standardized mean difference}

\section{Acknowledgements}

Not applicable.

\section{Authors' contributions}

SG, CC, WTL, and CM conceived the study, drafted the study design and search protocol. CC and WTL conducted the search, critical appraisal, and meta-analysis. SG and CM refined the study design and search protocol, participated in the study rating, helped draft the manuscript, and contributed to the background literature. All authors read and approved the final manuscript.

\section{Funding}

This research received no specific grant from any funding agency in the public, commercial, or not-for-profit sectors.

\section{Availability of data and materials}

The datasets used and/or analyzed during the current study are available from the corresponding author on reasonable request.

Ethics approval and consent to participate

Not applicable.

\section{Consent for publication}

Not applicable.

\section{Competing interests}

Suzanne Gough is an Associate Editor of BMJ Simulation and Technology Enhanced Learning. She has no other competing interests.

Chiara Mosley, Christina Condon, and Wing Tung Lam have no competing interests to declare.

\section{Author details}

${ }^{1}$ Faculty of Health Sciences and Medicine, Bond University, Gold Coast, Queensland, Australia. ${ }^{2}$ Faculty of Health, Psychology and Social Care, Manchester Metropolitan University, Manchester, UK.

Received: 20 July 2020 Accepted: 2 November 2020

Published online: 19 November 2020

\section{References}

1. Ferkol T, Schraufnagel D. The global burden of respiratory disease. Ann Am Thorac Soc. 2014:11(3):404-6.

2. Andersson M, Slinde F, Groenberg A, Svantesson U, Janson C, Emtner M. Physical activity level and its clinical correlates in chronic obstructive pulmonary disease: a cross-sectional study. Respir Res. 2013;14(1):128.

3. Troosters T, Langer D, Vrijsen B, Segers J, Wouters K, Janssens W, et al. Skeletal muscle weakness, exercise tolerance and physical activity in adults with cystic fibrosis. Eur Respir J. 2009;33(1):99-106.

4. Kim HC, Lee GD, Hwang YS. Skeletal muscle dysfunction in patients with chronic obstructive pulmonary disease. Tuberc Respir Dis. 2010;68(3):125-39.

5. Wearable Tech is New Top Fitness Trend for 2019, according to ACSM Survey. (2018, December 5). Retrieved December 5, 2018, from https://www. 
acsm.org/read-research/newsroom/news-releases/news-detail/2018/12/05/ wearable-tech-top-2019-fitness-trend.

6. Butler SJ, Lee AL, Goldstein RS, Brooks D. Active video games as a training tool for individuals with chronic respiratory diseases: a systematic review. Cardiopulm Rehabil Prev. 2019;39(2):85-90.

7. Gomes EL, Carvalho CR, Peixoto-Souza FS, Teixeira-Carvalho EF, Mendonça $J F$, Stirbulov R, et al. Active video game exercise training improves the clinical control of asthma in children: randomized controlled trial. PLOS ONE. 2015;10(8):e0135433

8. Almeida P, Rodrigues F. Exercise training modalities and strategies to improve exercise performance in patients with respiratory disease. Revista Portuguesa de Pneumologia (English Edition). 2014;20(1):36-41.

9. Holmes H, Wood J, Jenkins S, Winship P, Lunt D, Bostock S, et al. Xbox Kinect (TM) represents high intensity exercise for adults with cystic fibrosis. J Cyst Fibros. 2013;18:604-8.

10. Burr JF, Davidson W, Shephard RJ, Eves N. Physical activity in chronic respiratory conditions: assessing risks for physical activity clearance and prescription. Can Fam Physician. 2012;58(7):761-4.

11. Del Corral T, Percegona J, Seborga M, Rabinovich RA, Vilaró J. Physiological response during activity programs using Wii-based video games in patients with cystic fibrosis (CF). J Cyst Fibros. 2014;13(6):706-11.

12. Rutkowski S, Rutkowska A, Jastrzębski D, Racheniuk H, Pawełczyk W, Szczegielniak J. Effect of virtual reality-based rehabilitation on physical fitness in patients with chronic obstructive pulmonary disease. J Hum Kinet. 2019;15:117-24. https://doi.org/10.2147/COPD.S223592. eCollection 2020.

13. Simmich J, Deacon AJ, Russell TG. Active video games for rehabilitation in respiratory conditions: systematic review and meta-analysis. JMIR Serious Games. 2019;7(1):e10116.

14. Chuang TY, Chen $\mathrm{CH}$, Chang HA, Lee HC, Chou CL, Doong JL. Virtual reality serves as a support technology in cardiopulmonary exercise testing. Presence. 2003;12(3):326-31.

15. Sánchez TI, Salmerón MY, López LL, Rubio OA, Torres RJ, Valenza MC. Videogames in the treatment of obstructive respiratory diseases: a systematic review. Games Health J. 2019;8(4):237-49.

16. Moher D, Liberati A, Tetzlaff J, Altman D. Preferred reporting items for systematic reviews and meta-analysis: the PRISMA statement. Ann Int Med. 2009;151(4):264-9.

17. Liu W-Y, Meijer K, Delbressine JM, Willems PJ, Franssen FME, Wouters EFM, et al. Reproducibility and validity of the 6-minute walk test using the gait real-time analysis interactive lab in patients with COPD and healthy elderly. PLOS ONE. 2016;11(9):e0162444.

18. Moola S, Munn Z, Tufanaru C, Aromataris E, Sears K, Sfetcu R, Currie M, Lisy K, Qureshi R, Mattis P, Mu P. Chapter 7: Systematic reviews of etiology and risk. In: Aromataris E, Munn Z (Editors). JBI Manual for Evidence Synthesis. JBI, 2020. Available from https://synthesismanual.jbi.global, https://doi.org/ 10.46658/JBIMES-20-08

19. Del Corral T, Cebrià I, Iranzo MA, López-de-Uralde-Villanueva I, MartínezAlejos R, Blanco I, Vilaró J. Effectiveness of a home-based active video game programme in young cystic fibrosis patients. Respiration. 2018;95(2):87-97.

20. Sutanto YS, Makhabah DN, Aphridasari J, Doewes M. Suradi, Ambrosino N. Videogame assisted exercise training in patients with chronic obstructive pulmonary disease: a preliminary study. Pulmonology. 2019;25(5):275-82.

21. Kuys SS, Hall K, Peasey M, Wood M, Cobb R, Bell SC. Gaming console exercise and cycle or treadmill exercise provide similar cardiovascular demand in adults with cystic fibrosis: a randomised cross-over trial. J Physiother. 2011;57(1):35-40.

22. LeGear T, LeGear M, Preradovic D, Wilson G, Kirkham A, Camp PG. Does a Nintendo Wii exercise program provide similar exercise demands as a traditional pulmonary rehabilitation program in adults with COPD? Clin Respir J. 2016;10(3):303-10

23. Salonini E, Gambazza S, Meneghelli I, Tridello G, Sanguanini M, Cazzarolli C et al. Video game playing in children and adolescents with cystic fibrosis: exercise or just fun? Respir Care. 2015;60(8):1172-9.

24. Frade MC, Dos Reis IM, Basso-Vanelli RP, Brandão AF, Jamami M. Reproducibility and validity of the 6-minute stationary walk test associated with virtual reality in subjects with COPD. Respir Care. 2019;64(4):425-33.

25. O'Donovan C, Greally P, Canny G, McNally P, Hussey J. Active video games as an exercise tool for children with cystic fibrosis. J Cyst Fibros. 2014;13(3): 341-6.
26. Carbonera RP, Vendrusculo FM, Donadio MV. Physiological responses during exercise with video games in patients with cystic fibrosis: a systematic review. Respir Med. 2016;119:63-9.

27. Porritt K, Gomersall J, Lockwood C. JBI's systematic reviews: study selection and critical appraisal. Am J Nurs. 2014;114(6):47-52.

28. Buccheri RK, Sharifi C. Critical appraisal tools and reporting guidelines for evidence-based practice. Worldviews Evid Based Nurs. 2017;14(6):463-72.

29. Tufanaru C, Munn Z, Aromataris E, Campbell J, Hopp L. Chapter 3: Systematic reviews of effectiveness. In: Aromataris E, Munn Z (Editors). JBI Manual for Evidence Synthesis. JBI, 2020. Available from https:// synthesismanual.jbi.global, https://doi.org/10.46658/JBIMES-20-04.

30. McHugh M. Interrater reliability: the kappa statistic. Biochemia Medica. 2012; 22(3):276-82.

31. Suurmond R, van Rhee $H$, Hak T. Introduction, comparison and validation of meta-essentials: a free and simple tool for meta-analysis. Res Synth Methods. 2017:8(4):537-53.

32. Cohen J. Statistical power analysis for the behavioral sciences 2 nd ed. United States of America: Lawrence Erlbaum Associates; 1988.

33. Mazzoleni S, Montagnani G, Vagheggini G, Buono L, Moretti F, Dario P, et al. Interactive videogame as rehabilitation tool of patients with chronic respiratory diseases: preliminary results of a feasibility study. Respir Med. 2014;108(10):1516-24.

34. Burkow TM, Vognild LK, Johnsen E, Bratvold A. Promoting exercise training and physical activity in daily life: a feasibility study of a virtual group intervention for behaviour change in COPD. BMC Med Inform Decis Mak. 2018;18(1):136.

35. Albores J, Marolda C, Haggerty M, Gerstenhaber B, Zuwallack R. The use of a home exercise program based on a computer system in patients with chronic obstructive pulmonary disease. J Cardiopulm Rehabil Prev. 2013; 33(1):47-52.

36. Bingham PM, Lahiri T, Ashikaga T. Pilot trial of spirometer games for airway clearance practice in cystic fibrosis. Respir Care. 2012;57(8):1278-84.

37. Hoffman AJ, Brintnall RA, Brown JK, Eye AV, Jones LW, Alderink G, et al. Too sick not to exercise: using a 6-week, home-based exercise intervention for cancer-related fatigue self-management for postsurgical non-small cell lung cancer patients. Cancer Nurs. 2013;36(3):175-88.

38. Yuen HK, Lowman JD, Oster RA, de Andrade JA. Home-based pulmonary rehabilitation for patients with idiopathic pulmonary fibrosis: a PILOT STUDY. J Cardiopulm Rehabil Prev. 2019;39(4):281-4.

39. Wardini R, Dajczman E, Yang N, Baltzan M, Préfontaine D, Stathatos M, et al. Using a virtual game system to innovate pulmonary rehabilitation: safety, adherence and enjoyment in severe chronic obstructive pulmonary disease. Can Respir J. 2013;20(5):357-61.

40. Aromataris E, Fernandez R, Godfrey CM, Holly C, Kahlil H, Tungpunkom P. Summarizing systematic reviews: methodological development, conduct and reporting of an umbrella review approach. Int J Evid Based Healthc. 2015;13(3):132-40

41. Landis J, Koch G. The measurement of observer agreement for categorical data. Biometrics. 1977;33(1):159. https://doi.org/10.2307/2529310.

42. Shiraev T, Barclay G. Evidence based exercise: clinical benefits of high intensity interval training. Aust Fam Physician. 2012;41(12):960.

43. Millet GP, Vleck VE, Bentley DJ. Physiological differences between cycling and running. Sports Med. 2009;39(3):179-206.

44. Crisafulli $\mathrm{E}$, Clini EM. Measures of dyspnea in pulmonary rehabilitation. Multidiscip Respir Med. 2010;5(3):202.

45. Sharma S, Hashmi MF, Badireddy M. Dyspnea on exertion (DOE) [Updated 2019 Nov 23]. In: StatPearls [Internet]. Treasure Island (FL): StatPearls Publishing; 2020 Jan-. Available from: https://www.ncbi.nlm.nih.gov/books/ NBK499847/.

46. De Jong W, Van Der Schans CP, Mannes GPM, Van Aalderen WMC, Grevink RG, Koeter GH. Relationship between dyspnoea, pulmonary function and exercise capacity in patients with cystic fibrosis. Respir Med. 1997;91(1):41-6.

\section{Publisher's Note}

Springer Nature remains neutral with regard to jurisdictional claims in published maps and institutional affiliations. 